\title{
Representações Sociais de Estudantes de Engenharia Civil e Ambiental Sobre o Rio Doce
}

\section{Social Representations of Civil and Environmental Engineering Students about Rio Doce}

\author{
Renata Bernardes Faria Campos*a; Jacqueline Martins de Carvalho Vasconcelos ${ }^{\mathrm{b}}$; Gabriel Peçanha Brito Garciac; \\ Karla Ferreira de Carvalho Aguiarc; Matheus Pereira Carlech Guimarães ${ }^{\mathrm{c}}$
}
${ }^{a}$ Universidade Vale do Rio Doce, Programa de Pós-Graduação Stricto Sensu em Gestão Integrada do Território. MG, Brasil.

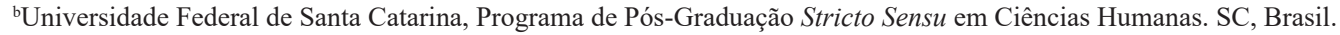
${ }^{c}$ Universidade Vale do Rio Doce. MG, Brasil.
*E-mail: rbfcampos@gmail.com

\begin{abstract}
Resumo
Os grandes desastres da atualidade e a relação entre o desenvolvimento e devastação da natureza evidenciam a necessidade de se reavaliar o modo de pensar das pessoas, entre os quais o presente trabalho destaca profissionais, cujas ações interferem direta e fortemente sobre a relação entre tecnologia e ambiente. Na presente pesquisa foi realizada uma análise das representações sociais de estudantes de Engenharia Civil e Ambiental sobre o Rio Doce, tomando como referência o levantamento de dados feito com base em questionários respondidos por estudantes de diferentes períodos do curso. Utilizou-se a técnica de livre associação de palavras e, em seguida, uma sistematização das evocações coletadas. Observou-se que a água, enquanto recurso necessário para os seres humanos, é central para os entrevistados, revelando uma representação antropocêntrica e utilitarista da mesma, sendo essa quase que exclusivamente qualificada como recurso. Por outro lado, também o elemento desastre compareceu no núcleo central, assim como a poluição que remete à degradação histórica do Rio Doce. O olhar detalhado para o processo de construção das representações dos estudantes e os efeitos da formação destes sujeitos ao longo da graduação evidencia que a graduação tem influência importante na ampliação do olhar dos engenheiros para o ambiente. Nesse sentido, destaca-se a importância da Educação Ambiental e formação crítica no Ensino Superior, como forma de ampliar a compreensão dos futuros profissionais.
\end{abstract}

Palavras-chave: Concepção. Engenheiros. Desastre. Sustentabilidade. Ambiente.

\begin{abstract}
Today's major disasters and the relationship between the development and devastation of nature highlight the need to reevaluate people's thinking, among which the current study highlights professionals whose actions directly and strongly interfere with the relationship between technology and the environment. In the present research, an analysis was performed of the social representations of Civil and Environmental Engineering students about Rio Doce, taking as reference the data survey based on questionnaires answered by students from different periods of the course. The technique of free word association was used and then a systematization of collected evocations. It was observed that water, as a necessary resource for humans, is central to the interviewees, revealing an anthropocentric and utilitarian representation of it, which is almost exclusively qualified as a resource. On the other hand, the element disaster also appeared in the central nucleus, as well as the pollution that refers to the historical degradation of Rio Doce. A detailed look at the process of constructing students 'representations and the effects of their formation throughout undergraduate shows that undergraduate studies have an important influence on the broadening of the engineers' look at the environment. In this sense, it is highlighted herein the importance of Environmental Education and critical training in higher education, as a way to broaden the understanding of future professionals.
\end{abstract}

Keywords: Conception. Engineers. Disaster. Sustainability. Environment.

\section{Introdução}

Especialmente após a Revolução Industrial, diversas áreas da Engenharia e de modo particular a Mecânica e Civil, cresceram de forma quase ininterrupta, trazendo novas tecnologias, ampliando fronteiras, abastecendo a economia e promovendo o "controle" pelo ser humano sobre o mundo (CAVALCANTE; SILVA, 2011). Como resultado desse processo, atualmente, os incrementos tecnológicos afetam positivamente a qualidade de vida das pessoas, mas suas consequências acarretam também riscos e desastres tecnológicos, tornando evidente que ciência e técnica não desenvolveram suficientemente suas capacidades de prever e controlar a relação entre os benefícios trazidos e os riscos decorrentes de tais benefícios (BECK, 2018). Diante da preocupação em aliar o desenvolvimento tecnológico e econômico com a conservação e recuperação do ambiente, o presente artigo considera o desafio que deriva dos conflitos entre aspectos socioeconômicos, tecnológicos e ambientais, questão que se apresenta como um dos grandes desafios para a engenharia do século XXI (BRAGA et al., 2005).

É possível observar que a construção civil está diretamente interligada ao meio ambiente, pois grande parte dos materiais retirados da natureza, anualmente, são utilizados em canteiros de obras e construções (SPADOTTO et al., 2011). Por outro lado, destacam-se os benefícios econômicos e sociais que a engenharia e construção civil trazem, uma vez que surgem como responsáveis por $6,2 \%$ do produto interno bruto (PIB) do Brasil, além de gerar 2,6 bilhões de emprego, representando 
$24 \%$ do total do país, de acordo com a Federação das indústrias do Distrito Federal (FIBRA, 2017). Porém, com a crescente degradação ambiental e o aumento na frequência de desastres tecnológicos somados ao fato de que nenhum país coloca metas de redução de impactos ambientais acima de suas metas de crescimento econômico (MARQUES, 2016), fica cada vez mais evidente a necessidade de se repensar a engenharia e sua relação com o ambiente.

As discussões sobre a importância da Educação Ambiental na formação de engenheiros têm sido constantes, dado que as diretrizes curriculares nacionais preconizam o entendimento dos impactos de suas ações, conforme cita o inciso XI do artigo $4^{\circ}$ da Resolução CNE/CES 11, de 11 de março de 2002, em que "avaliar o impacto das atividades de engenharia no contexto social e ambiental" é parte essencial da formação desses profissionais. Esta questão se torna ainda mais importante na bacia do Rio Doce, que sofre as consequências de um dos maiores desastres envolvendo barragens de mineração, que comprometeu ecossistemas ciliares e aquáticos, ceifou 19 vidas humanas e outros inúmeros seres vivos, deixando ainda comunidades inteiras desabrigadas no ano de 2015 (MILANEZ; LOSEKANN, 2016). E é justamente nesse contexto que no presente artigo são analisadas as representações sociais de estudantes de engenharia do Leste de Minas Gerais sobre o desastre do Rio Doce.

Considera-se aqui a engenharia como uma construção coletiva, isto é, uma resposta de anseios individuais catapultados para um coletivo sociocultural (BAZZO; PEREIRA, 1997). Isso implica dizer que a engenharia não se restringe apenas ao estudo de matérias exatas, naturais e cálculos, mas também a uma cooperação direta e indireta com a melhoria da qualidade de vida. Os engenheiros têm papel essencial para o desenvolvimento tecnológico por serem profissionais associados aos processos, melhoria de produtos, produção, gestão de métodos produtivos e atividades de inovação, pesquisa e desenvolvimento (DAGNINO; NOVAES; FRAGA, 2013). Dessa forma, o engenheiro expressa o papel de um sujeito que interage continuamente com seu trabalho e seus entornos social e histórico, como cita Milititsky (1998), sendo a pessoa que se inter-relaciona nas construções, aceitando, até certo ponto, o pensamento difundido pelo senso comum (HOLTZAPPLE; REECE, 2014).

Segundo dados do IBGE (2001), no Brasil, o grau de urbanização passou de 75,59\% em 1991 para 81,23\% em 2000. Em um contexto de urbanização crescente e inadequada, se faz importante a figura do engenheiro. E em contraponto à franca evolução da atividade da construção civil, pesquisadores apontam que a ênfase crescente na inovação, a busca por qualidade de vida, o envelhecimento da população e a preocupação com o meio ambiente serão importantes impulsionadores das carreiras mais promissoras nos próximos anos (WRIGHT; SILVA; SPERS, 2010).
Nesse sentido, a inovação que tem sido apontada como a principal tendência no mercado de trabalho, vem associada à qualidade de vida e com a preocupação com o meio ambiente. Logo, espera-se uma "pressão pela busca de alternativas de baixo impacto ambiental, seja na fase de desenvolvimento, produção/processo, seja na fase de descarte ou, no limite, na redução da poluição resultante" (WRIGHT; SILVA; SPERS, 2010). Nesse panorama de busca pela integração entre engenharia e ambiente, interessa o conhecimento das representações sociais dos engenheiros em formação sobre o próprio meio natural.

Embora Moscovici (1981) tenha inaugurado o termo em questão, outros autores propuseram diferentes definições para este conceito. Jodelet (1989 apud SÁ, 1996) cita como objetivo das representações a finalidade da construção de uma realidade comum a um conjunto social, sendo a representação, para tanto, uma construção e uma expressão do sujeito, que pode ser considerado também social ou coletivo, pois integra nas análises o pertencimento e a participação social e cultural do sujeito.

Outras questões criaram diferenças entre os conceitos e definições de representações sociais. A própria denominação "social", em vez de "coletivas" (SÁ, 1996), sendo a última denominação utilizada por Durkheim, o qual teria um "conceito perdido" das representações, em acordo com Moscovici (1981). Segundo este autor, representações coletivas são definidas por sua oposição às representações individuais, sendo essa oposição irrelevante, e que as representações podem ser partilhadas por todos os membros de um grupo altamente estruturado, sem terem sido produzidas por este mesmo grupo.

Sá (1996) destaca que a exigência explicativa de natureza psicossociológica marca uma importante diferença em relação ao tratamento sociológico anterior de representações coletivas de Durkheim, já que as representações coletivas eram vistas como explicativas nessas mesmas, independentemente de qualquer análise, ao passo que as representações sociais são consideradas fenômenos que devem ser eles próprios explicados, sendo passíveis de interpretações posteriores.

Por fim, Sá (1996) justifica a criação das representações, para compreensão desse fenômeno, afirmando que o propósito de todas representações é transformar algo não familiar, em familiar. A representação seria capaz de aplicar a um objeto não-presente um sentido, tornando-o "tangível", tornando concreto um conceito antes abstrato, materializando a palavra.Sentido significa construção social, empreendimento coletivo, mais precisamente interativo, por meio do qual as pessoas constroem os termos, a partir dos quais compreendem e lidam com as situações e fenômenos a sua volta (SPINK, 1993; MEDRADO, 2004), e sua elaboração ocorre pela prática social, pela maneira como as pessoas se estabelecem nas relações sociais cotidianas, divididos em sentidos de um tempo longo, vivido, e tempo curto. 
Nesse sentido, o presente estudo investiga as representações sociais dos estudantes de Engenharia Civil e Ambiental em diferentes períodos da graduação acerca do "ambiente", termo de atual relevância na engenharia, utilizando para tal a expressão "Rio Doce" como tema indutor.

\section{Material e Métodos}

Este trabalho foi realizado em Governador Valadares, município localizado no Leste de Minas Gerais, na Bacia do Rio Doce. A região tem sofrido, historicamente, com a degradação ambiental, que se intensificou ao longo da segunda metade do século passado, sendo a região de Governador Valadares com menor conservação da área de floresta da bacia (COMPANHIA VALE DO RIO DOCE, 1969).

O município é também formador de engenheiros há mais de quatro décadas, sendo a Univale pioneira em cursos de engenharia e, particularmente, no curso de dupla habilitação em Engenharia Civil e Ambiental, formando novos engenheiros para atuar na construção civil, por meio do planejamento e acompanhamento da execução de obras e, também, em atividades ligadas ao ambiente, como saneamento, recuperação de áreas degradadas, entre outras que visam contribuir para a qualidade de vida (UNIVALE, 2017).

O estudo qualitativo-quantitativo foi executado a partir dos dados levantados com os estudantes participantes três anos após o desastre decorrente do rompimento da Barragem de Fundão em Mariana, MG, por meio da aplicação dos questionários, elaborados de acordo com Técnica de Livre Associação de Palavras (TALP) (NEVES et al., 2014). Foram convidados para participar, voluntariamente, todos os estudantes regularmente matriculados e frequentes das cinco turmas (segundo, quarto, sexto, oitavo e décimo períodos) do curso de dupla habilitação em Engenharia Civil e Ambiental da Universidade Vale do Rio Doce - UNIVALE. Dos 130 estudantes regularmente matriculados, os que estavam presentes no dia da entrevista leram e assinaram o Termo de Consentimento Livre e Esclarecido (TCLE). Portanto, foram excluídos somente aqueles que estiveram ausentes da Universidade nos dias da aplicação do questionário ou que manifestassem seu desejo de não participar.

Solicitou-se a cada entrevistado, por meio de um questionário impresso, que evocasse por escrito, as cinco primeiras palavras ou expressões sobre o "Rio Doce" que lhe viessem à mente. Após anotarem os cinco primeiros termos lembrados, foi solicitado que cada entrevistado reordenasse os termos em função da sua importância. Em seguida se solicitou que cada entrevistado justificasse por escrito o motivo pelo qual destacou aquele termo como o mais importante entre suas próprias evocações.

Na presente pesquisa, considera-se que "as representações são ao mesmo tempo estáveis e móveis, rígidas e flexíveis" (ABRIC, 1994, p.77); e "as representações são consensuais, mas também marcadas por fortes diferenças interindividuais" (p.78). Dessa forma, as informações resultantes da aplicação da TALP foram tabuladas e os termos evocados pelos alunos foram agrupados, quando o significado ou sentido era semelhante como "sujo" e "sujeira", "trágico" e "tragédia" ou "peixe" e "peixes". Os dados tabulados foram então processados com o auxílio do software Ensemble de Programmes Permettrantl'Analysedes Évocations (EVOC), separadamente para cada uma das turmas participantes. Dessa forma, procedeu-se a sistematização e o controle das evocações dos participantes, por meio de um levantamento estatístico, que indica quais os elementos constitutivos dos núcleos centrais e periféricos das representações a partir do cálculo de frequência $(\mathrm{F})$ dada pelo número de entrevistados que evocou o termo ou expressão em questão e da ordem média de evocação (OME), inferida a partir da importância dada a cada termo pelos entrevistados (OLIVEIRA et al., 2005).

A frequência das evocações foi utilizada para avaliar o grau de compartilhamento das mesmas no grupo pesquisado: quanto mais frequente, mais compartilhada é a palavra (SCHUCH et al. 2013). A OME foi considerada como um índice de saliência: a evocação mais importante significa que a palavra está mais acessível na memória de trabalho do sujeito, sendo facilmente ativada pelo estímulo indutor, o que sugere uma forte ligação com o mesmo. Segundo Sá (1996, p. 117), “A combinação desses dois critérios, frequência de evocação e ordem média de evocação de cada palavra, possibilita o levantamento daquelas que mais provavelmente pertencem ao núcleo central da representação".

Segundo o protocolo adotado (SÁ, 1996), as palavras agrupadas no quadrante superior esquerdo (aqui chamado primeiro quadrante), que possuem as maiores frequências e são as principais evocadas, formam o núcleo central da representação social. O sistema periférico, por sua vez, localiza-se nos quadrantes superior e inferior direito (aqui chamados segundo e quarto quadrantes), respectivamente, primeira e segunda periferia. Os elementos de contraste (aqui chamado segundo quadrante) se encontraram no quadrante inferior esquerdo.

Para a composição dos quadrantes, foram definidas arbitrariamente frequências e ordens médias de evocação que variaram entre as turmas em função do número de estudantes. Estes valores são estabelecidos a fim de se obter para o núcleo central da representação uma relação até cinco elementos e, assim, ter condições de construir uma ideia da representação.

\section{Resultados e Discussão}

Todos os estudantes convidados aceitaram responder o questionário, sem qualquer tipo de recusa em participar da pesquisa. Foram entrevistados 87 dos 130 estudantes matriculados, sem nenhuma resistência (Quadro 1). A diferença entre o número de matriculados e de participantes no estudo se deve a quantidade de estudantes ausentes nos dias das entrevistas. A média de idade geral não supera os 
22 anos, evidenciando a possibilidade de fundamentação de novos conceitos para um público jovem, com o andamento do curso. Os 151 diferentes termos evocados pelos entrevistados foram agrupados em 112 categorias.

Quadro 1 - Caracterização dos sujeitos da pesquisa

\begin{tabular}{|c|c|c|c|c|}
\hline Período & Alunos Entrevistados & Alunos Matriculados & $\begin{array}{c}\text { Participação em } \\
\text { Porcentagem }\end{array}$ & $\begin{array}{c}\text { Idade Média } \\
(\text { desvio padrão) }\end{array}$ \\
$2^{\text {o }}$ & 6 & 15 & $40 \%$ & $18,83(0,75)$ \\
$4^{\text {o }}$ & 9 & 15 & $60 \%$ & $21,33(3,97)$ \\
$6^{\text {o }}$ & 19 & 22 & $86 \%$ & $22,89(4,42)$ \\
$8^{\text {o }}$ & 22 & 37 & $60 \%$ & $22,45(3,34)$ \\
$10^{\text {o }}$ & 31 & 41 & $76 \%$ & $23,55(3,34)$ \\
Total & 87 & 130 & $67 \%$ & $22,59(3,63)$ \\
\hline
\end{tabular}

Fonte: Dados da pesquisa.

De modo geral, os resultados indicam que as representações sociais dos estudantes de Engenharia Civil e Ambiental sobre o Rio Doce podem ser entendidas como: um curso ou fonte de água, poluído, sendo destacado como consequência do desastre decorrente do derramamento de lama (rejeito de mineração) da Samarco, responsável, ainda, pela morte de peixes, contaminação da água e problemas socioambientais que afetam a bacia. Se por um lado a biodiversidade também compõe as representações, por outro o descarte de resíduos (esgoto) também é associado ao do Rio Doce (Quadro 2).

Quadro 2 - Quadros de Vergés do termo indutor "Rio Doce" para estudantes dos diversos períodos do Curso de dupla habilitação em Engenharia Civil e Ambiental em Governador Valadares, 2017.

\begin{tabular}{|c|c|c|c|c|c|}
\hline \multicolumn{6}{|c|}{$\mathbf{2}^{\circ}$ Período } \\
\hline Elementos do núcleo central & $\mathbf{F} \geq 3$ & $\mathrm{OME} \leq 4$ & Elementos do Sist. Periférico & $\mathbf{F} \geq 3$ & OME $\geq 4$ \\
\hline Poluição & 5 & 2,6 & Lama & 4 & 4 \\
\hline Elementos de contraste & $\mathbf{F} \geq \mathbf{3}$ & $\mathrm{OME} \leq 4$ & Elementos do Sist. Periférico & $\mathbf{F} \geq \mathbf{3}$ & OME $\geq 4$ \\
\hline Água & 2 & 3,5 & Lixo & 1 & 5 \\
\hline Degradação & 1 & 3 & Perda-espécies & 1 & 5 \\
\hline Desastre & 1 & 3 & Renda & 1 & 5 \\
\hline Desemprego & 1 & 3 & Turbidez & 1 & 5 \\
\hline Destruição-cultura-ribeirinha & 1 & 2 & Valadares & 1 & 4 \\
\hline Fome & 1 & 1 & Vale & 1 & 4 \\
\hline Fonte-vida & 1 & 1 & & & \\
\hline Irrigação & 1 & 2 & & & \\
\hline Metais & 1 & 1 & & & \\
\hline Samarco & 2 & 1,5 & & & \\
\hline \multicolumn{6}{|c|}{$4^{\circ}$ Período } \\
\hline Elementos do núcleo central & $\mathbf{F} \geq 3$ & $\mathrm{OME} \leq 4$ & Elementos do Sist. Periférico & $\mathbf{F} \geq \mathbf{3}$ & OME $\geq 4$ \\
\hline Desastre & 4 & 2,75 & 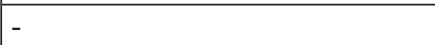 & - & - \\
\hline Lama & 4 & 2,75 & - & - & - \\
\hline Poluição & 3 & 1,67 & - & - & - \\
\hline Samarco & 3 & 2,75 & & - & - \\
\hline Elementos de contraste & $\mathbf{F} \geq 3$ & $\mathrm{OME} \leq 4$ & Elementos do Sist. Periférico & $\mathbf{F} \geq \mathbf{3}$ & OME $\geq 4$ \\
\hline Água & 1 & & Assoreamento & 1 & 5 \\
\hline Barragem & 1 & & Ilha & 1 & 5 \\
\hline Biodiversidade & 2 & & Impureza & 1 & 5 \\
\hline Contaminação & 1 & & Mineração & 1 & 4 \\
\hline Degradação & 1 & & Peixes & 1 & 5 \\
\hline Desequilíbrio-ecológico & 1 & & Pesca & 2 & 4,4 \\
\hline Importante & 1 & & Recursos-hídricos & 1 & 4 \\
\hline Morte & 2 & & SAAE** & 1 & 4 \\
\hline \multirow[t]{2}{*}{ PERD* } & 1 & & Sujo & 2 & 4,5 \\
\hline & & & Sustentabilidade & 1 & 5 \\
\hline \multicolumn{6}{|c|}{$6^{0}$ Período } \\
\hline Elementos do núcleo central & $\mathbf{F} \geq \mathbf{5}$ & $\mathrm{OME} \leq \mathbf{3}$ & Elementos do Sist. Periférico & $\mathbf{F} \geq \mathbf{5}$ & $O M E \geq 3$ \\
\hline Desastre & 9 & 2,44 & Lama & 6 & 3,67 \\
\hline Poluição & 8 & 2,38 & Peixe & 5 & 3,4 \\
\hline
\end{tabular}




\begin{tabular}{|c|c|c|c|c|c|}
\hline Elementos de contraste & $\mathbf{F} \geq \mathbf{5}$ & $\mathrm{OME} \leq \mathbf{3}$ & Elementos do Sist. Periférico & $\mathbf{F} \geq \mathbf{5}$ & OME $\geq 3$ \\
\hline Acidente-Samarco & 1 & 2 & Abandono & 1 & 4 \\
\hline Água-potável & 1 & 1 & Abastecimento & 1 & 4 \\
\hline Contaminação & 3 & 2,33 & Água & 4 & 4,25 \\
\hline Descarte-resíduos & 1 & 2 & Ambiente & 1 & 5 \\
\hline Descaso & 1 & 2 & Assoreamento & 1 & 4 \\
\hline Descuido & 1 & 2 & Biodiversidade & 1 & 5 \\
\hline Falta-conscientização & 1 & 1 & Cultura-indígena & 1 & 3 \\
\hline Impacto-ambiental & 4 & 2 & Dano-ambiental & 1 & 3 \\
\hline Impacto-social & 1 & 2 & Degradação & 1 & 3 \\
\hline Perda & 1 & 1 & Doença & 1 & 4 \\
\hline \multicolumn{6}{|c|}{$8^{0}$ Período } \\
\hline Elementos do núcleo central & $\mathbf{F} \geq \mathbf{5}$ & $\mathrm{OME} \leq \mathbf{3}$ & Elementos do Sist. Periférico & $\mathbf{F} \geq \mathbf{5}$ & $\mathrm{OME} \geq 3$ \\
\hline Abastecimento & 7 & 2,29 & Lama & 10 & 4,2 \\
\hline Água & 8 & 1,75 & Poluição & 9 & 3 \\
\hline Desastre & 12 & 2,54 & Samarco & 6 & 3,83 \\
\hline Elementos de contraste & $\mathbf{F} \geq \mathbf{1 0}$ & $\mathrm{OME} \leq \mathbf{3}$ & Elementos do Sist. Periférico & $\mathbf{F} \geq \mathbf{1 0}$ & $\mathrm{OME} \geq 3$ \\
\hline Barragem & 1 & 1 & Acidente-Samarco & 4 & 3 \\
\hline Biodiversidade & 4 & 2 & Assoreamento & 4 & 4,25 \\
\hline Captação-água & 1 & 2 & Características-cidade & 1 & 3 \\
\hline Contaminação & 3 & 2,67 & Chuva & 1 & 5 \\
\hline Esgoto-sanitário & 1 & 2 & Degradação & 1 & 5 \\
\hline Extinção & 1 & 1 & Esgoto & 1 & 5 \\
\hline Impacto-ambiental & 2 & 2,5 & Extinção & 1 & 3 \\
\hline Natureza & 1 & 2 & Extinção-espécies & 2 & 3,5 \\
\hline Peixes & 3 & 2,67 & Falta-água & 2 & 4 \\
\hline Perda & 1 & 2 & Governador-Valadares & 1 & 5 \\
\hline \multicolumn{6}{|c|}{$10^{\circ}$ Período } \\
\hline Elementos do núcleo central & $\mathbf{F} \geq \mathbf{5}$ & OME $\leq 3$ & Elementos do Sist. Periférico & $\mathbf{F} \geq \mathbf{5}$ & OME $\geq 3$ \\
\hline Água & 16 & 2 & Lama & 9 & 3 \\
\hline Biodiversidade & 6 & 2 & Peixes & 5 & 3,6 \\
\hline Desastre & 11 & 2,82 & Pesca & 7 & 3,57 \\
\hline Poluição & 12 & 2,42 & Samarco & 10 & 3,3 \\
\hline Vida & 9 & 1,67 & Sujeira & 5 & 4,4 \\
\hline Elementos de contraste & $F \geq 5$ & $\mathrm{OME} \leq \mathbf{3}$ & Elementos do Sist. Periférico & $F \geq 10$ & OME $\geq 3$ \\
\hline Ambiente & 2 & 2,5 & Abastecimento & 3 & 3 \\
\hline Bacia-hidrográfica & 1 & 2 & Algodão-doce & 1 & 5 \\
\hline Descaso & 1 & 1 & Barragem & 2 & 4 \\
\hline Enchente & 1 & 2 & Chocolate & 1 & 4 \\
\hline Falta-compaixão-vida & 1 & 2 & Crise-hídrica & 1 & 4 \\
\hline Falta-competência & 1 & 1 & Degradação & 4 & 4,25 \\
\hline Identidade & 1 & 2 & Dependência & 1 & 5 \\
\hline Impunidade & 1 & 1 & Escassez & 1 & 4 \\
\hline Injustiça & 1 & 1 & Esgoto & 1 & 4 \\
\hline Nascente & 1 & 2 & Extincão & 1 & 3 \\
\hline
\end{tabular}

*Parque Estadual do Rio Doce; **Sistema Autônomo de Abastecimento e Esgoto

Fonte: Dados da pesquisa.

Assim como Vasconcelos (2017) encontrou para crianças, na presente pesquisa, a palavra "água" surge no núcleo central das representações sociais de estudantes do final do Curso de Engenharia em Governador Valadares. Na maioria de suas justificativas, os graduandos destacam a relação primordial da "água" com a sobrevivência e com a "vida", palavra que também compõe o núcleo central:

Não existe vida sem a água (Estudante $\mathrm{A}, 10^{\circ}$ Período).

Essencial para a sobrevivência do ser humano, por isso é importante manter sua qualidade (Estudante $\mathrm{B}, 10^{\circ}$ Período).
Pois a escassez hídrica e racionalização deste recurso tem prejudicado diversas pessoas, sendo que a água é essencial para a sobrevivência humana (Estudante $\mathrm{C}, 8^{\circ}$ Período).

As palavras biodiversidade e vida, que também compõem o núcleo central das representações sociais do Rio Doce de estudantes do décimo período, aparecem se referindo a “qualquer ser vivo" (Estudante D, $10^{\circ}$ Período). Isso remete à percepção do rio inserido em um sistema amplo, no qual diversos seres coexistem e, particularmente, no caso do elemento "vida", a justificativa para sua importância está 
associada ao significado da palavra em si de modo abrangente, mas com pouca ligação explícita com o rio:

Pois tudo que acontece parte da vida, de forma total e absoluta (Estudante E, $10^{\circ}$ Período).

Pois é a base de tudo (Estudante N, $2^{\circ}$ Período).

Entretanto, nas justificativas para a evocação da palavra “água”, em primeiro lugar, há o predomínio de seu valor enquanto recurso, o que inclusive se relaciona com o fato de "abastecimento" comparecer no núcleo central do oitavo período, conforme é possível notar nas justificativas daqueles que apontam "abastecimento" como o elemento mais importante:

Pois afeta diretamente toda a população no que diz respeito a qualidade da água, já que esta deve ser fornecida em parâmetros aceitáveis. (Estudante X, $8^{\circ}$ Período).

Pelo fato de água ser um recurso muito importante para a saúde pública e para a sociedade. (Estudante Z, $8^{\circ}$ Período).

A água também é lembrada na condição de recurso valorizado por seu uso acima de sua importância ecológica, ainda que essa apareça, muitas vezes, associada à vida de modo geral. Nesse mesmo sentido, compareceram justificativas que conectaram a importância da água para necessidades e atividades sociais, e a relevância de se preservá-la enquanto recurso para uso humano:

Porque usufruímos das águas que correm o Rio Doce (Estudante E, $8^{\circ}$ Período).

Nós necessitamos de água para sobrevivermos, suprir nossas necessidades, por isso precisamos preservar para que ela não acabe (Estudante $\mathrm{F}, 10^{\circ}$ Período).

Porque a água é necessária para todos, e precisamos nos atentar para a proteção desse recurso (Estudante G, $8^{\circ}$ Período).

O elemento "biodiversidade" se relaciona direta e negativamente com o impacto decorrente do rompimento da barragem da mineradora Samarco em 2015. Dessa forma, "biodiversidade" aparece ligada às palavras como "desastre" e à preocupação com o futuro:

Porque a biodiversidade foi muito impactada com o desastre que aconteceu, e depois da lama da Samarco, se nós não tomarmos atitudes para proteger e mitigar os impactos, talvez o rio nunca volte a ser o que era (Estudante $\mathrm{J}, 10^{\circ}$ Período).

Os elementos "desastre" e "lama" se destacam pela frequência total de evocações (38 e 33 respectivamente) e, ainda, que esta última componha o núcleo central somente entre alunos do quarto período, figura na primeira periferia de todos os demais. As justificativas indicam que o desastre ocorrido três anos antes das entrevistas foi memorizado, e ao que indica, poderá ser lembrado por um tempo até então indeterminado, assim como suas consequências. A maioria das justificativas daqueles que consideram "lama" como o termo mais importante leva ao indicativo de tristeza e pesar com a situação atual do rio, apontado inclusive por um sentimento de familiarização com a utilização de expressões como "nosso rio":

Porque a lama estragou o Rio Doce, contaminando nosso rio (Estudante P, $10^{\circ}$ Período).

Pelo fato de ter ocasionado impactos irreversíveis tanto para a natureza quanto para a população (Estudante Q, $10^{\circ}$ Período). Pelas consequências que acarretou e possíveis danos a nossa saúde (Estudante R, $4^{\circ}$ Período).

No que se trata dos elementos periféricos, Abric apresenta que:

Os elementos periféricos são mais flexíveis, adaptam-se mais facilmente às transformações do contexto, aceitam mudanças sem que a representação central seja alterada de forma profunda. Respondem a três funções: concretização da representação; regulação ou adaptação da representação ao contexto; defesa e proteção do núcleo central dando conta das contradições (ABRIC, 1998 apud TECHIO; GONÇALVES; COSTA, 2016, p. 193-194).

Dessa forma, pode-se legitimar mais uma vez a proporção dos impactos provocados pelo desastre na representação dos graduandos, com forte e praticamente completa presença em todos os quadrantes, seja em palavras ou expressões, que estão diretamente conectadas ao desastre por indução lógica do contexto da representação no entorno das mesmas. Assim, embora os resultados concordem com Souza, Oliveira e Barbosa (2016), ao apontarem que o rio antes lembrado pela sua importância natural, social e econômica, passa a ser aventado como o "Vale do rio de lama".

Nesse sentido, ressalta-se ainda que a categoria "Samarco", que compõe o núcleo central do quarto período esteve presente nas evocações de todas as turmas, totalizando 25 (vinte e cinco) evocações, evidenciando a atenção para a responsabilidade, ainda que por cinco vezes associada à ideia de acidente. É possível notar o sentimento de revolta e o julgamento dos entrevistados, pelo fato de diferentemente das demais palavras do núcleo central e zona periférica, as justificativas não girarem em torno de consequências sofridas, mas sim de responsabilidade por efeitos provocados pela palavra em si:

Porque o acidente prejudicou as demais palavras/expressões, além de prejudicar a biodiversidade do rio (Estudante P, $6^{\circ}$ Período).

Pois é a principal responsável pelo que aconteceu ao rio doce (Estudante Q, $2^{\circ}$ Período).

Pois temos que dar mais foco para o desastre que a empresa Samarco causou (Estudante R, $10^{\circ}$ Período).

A palavra "poluição", que foi citada 37 (trinta e sete) vezes no total e apontada como a mais importante por 10 (dez) entrevistados, compõe o núcleo central de todos os períodos exceto o oitavo, no qual figura na primeira periferia, e remete ao histórico de degradação do rio reforçando a ideia do impacto ocasionado pelo desastre, assim como a preocupação com as futuras gerações.

Porque é o termo que representa o passado e o presente do rio, e ao mesmo tempo direciona para ações futuras. É a condição 
natural atual do rio e de quem causou o desastre que o poluiu mais ainda (Estudante $\mathrm{K}, 10^{\circ}$ período).

Pois a poluição é algo que percorre desde sempre o rio doce, que está mais poluído e que tem que ser tratado urgentemente (Estudante L, $4^{\circ}$ Período).

Devemos fazer um plano para o tratamento de esgoto a fim de melhorar isso no rio para gerações futura (Estudante M, $10^{\circ}$ Período)

Considera-se aqui o núcleo central como elemento que permite a realização de estudos comparativos das representações e que fornece significado à representação. Segundo Chaves e Silva (2013), estes elementos centrais se conectam à história e memória do grupo, com função geradora, organizadora e estabilizadora. Partindo desse contexto, a análise da composição do núcleo central demonstra que, independentemente da posição da palavra evocada, suas justificativas circundam os impactos vividos e/ou observados pelo grupo como um todo. Portanto, é preciso considerar que a "poluição" já era prontamente associada ao rio Doce, mesmo antes do desastre sociotécnico ${ }^{2}$ da Samarco (AMORIM et al. 2018), fato lembrado pelos entrevistados:

Mesmo antes do acidente da Samarco o rio Doce já era um dos mais poluídos do Brasil (Estudante $\mathrm{S}, 8^{\circ}$ Período).

[...] é o termo que representa o passado e o presente do rio, e ao mesmo tempo (Estudante T, $8^{\circ}$ Período).

Em princípio, pode-se concluir que há um predomínio dos aspectos ambientais nas representações aqui encontradas assim como também encontraram Techio, Gonçalves e Costa (2016). Entretanto, diferentemente desses autores, nota-se que as justificativas, ou seja, o significado destas evocações indica que a importância destes elementos "naturais" está justamente na sua função social, associada ao seu uso enquanto recurso. É provável que o desastre da Samarco e a privação no abastecimento de água por toda a população, em novembro de 2015 , tenha impactado a relação das pessoas com o rio. Dessa forma, embora os estudantes tenham evocado elementos ligados ao ambiente, fica evidente que o rio é entendido como fonte de recursos.

Nota-se também que, para estudantes da segunda metade do curso (sexto, oitavo e décimo períodos), o conhecimento técnico e geral sobre o ambiente como um todo é evocado de forma mais complexa do que os estudantes de períodos iniciais (Tabela 2). Embora em parte isso possa se dever ao número reduzido de estudantes e, consequentemente, o menor número de termos evocados nos primeiros períodos, o nível de ensino e a área de graduação, na qual se inserem os entrevistados, pode ser uma explicação complementar para as diferenças. $\mathrm{O}$ comparecimento de termos como biodiversidade no núcleo central dos estudantes do décimo período, por exemplo, contrasta com sua ausência entre as evocações dos estudantes do segundo período, e sua importância intermediária ao longo do curso, evidencia a provável importância da graduação para a formação das representações sociais de engenheiros.

Da mesma forma, termos periféricos como "lixo" e "perda de espécies" citados pelos estudantes do segundo período é substituído por "esgoto" ou "descarte de resíduos" e "extinção", respectivamente, nos períodos finais do curso, nomeadamente oitavo e décimo. No mesmo sentido, o elemento "abastecimento", considerado técnico, em análise, é evocado a partir do sexto período, inclusive, compondo o núcleo central no oitavo período.

Em todos os períodos, os termos: água, poluição e lama se destacam sugerindo que o rio faz parte de um ambiente tratado ora como "recurso" e ora como "problema", de forma antropocêntrica, sendo inclusive denominado dessa maneira nas justificativas. Essas representações, exceto pelo elemento lama, já faziam parte daquelas encontradas no núcleo central de moradores de Governador Valadares antes do desastre (AMORIM et al., 2018). Desse modo, se por um lado, o núcleo central das representações da população em geral se mantém entre os engenheiros em formação, por outro lado, há termos técnicos, como: "impacto ambiental" e "social", assim como "esgoto-sanitário", "dano ambiental", e "captação de água", que passam a compor a periferia das representações dos estudantes, a partir do quarto período do curso, evidenciando mais uma vez a influência da graduação para as representações sociais dos futuros profissionais.

Segundo Reigota (2004) e Spink (1993), as representações sociais podem ser definidas como o senso comum sobre determinado tema, em um contexto de construção no qual estão incluídos os preconceitos e as concepções que se relacionam com este tema. Seguindo o raciocínio, a interpretação da representação dos estudantes não apenas sobre a água, mas também as demais palavras de maior significância são importantes como balizadoras da Educação Ambiental no Ensino Superior, e o aprimoramento de programas voltados à sustentabilidade e ao desenvolvimento sustentável, seja em atividades teóricas ou práticas.

As diferenças entre as turmas, ao longo do curso, corroboram com Arruda (2002), evidenciando que as representações não são uma imagem fotográfica da realidade, mas estão em constante transformação, sendo, portanto, dinâmica e móvel. Nesse sentido, alerta-se para a importância de a Graduação buscar a superação da formação técnica dos engenheiros, assim como a necessidade de inserção de elementos voltados para a formação sociopolítica nos currículos (BORBA; DO AMARAL PORTO, 2014).

Lembra-se, ainda que para engenheiros, enquanto agentes multiplicadores e difusores de novos processos de trabalho, a inserção em programas de educação continuada, de conteúdo administrativo/gerencial e humanístico se torna imprescindível

2 Termo utilizado por Zhouri et. al. (2018, p.40) fazendo referência a esse desastre específico “[...] para enfatizar um processo deflagrado para além de uma avaria ou erro meramente técnico, remetendo-nos, assim, às falhas da governança ambiental, produtoras de novos padrões de vulnerabilidade que expuseram, de fato, a população ao risco". 
(LAUDARES; RIBEIRO, 2000). Portanto, percebe-se a demanda de investimento na apropriação de uma perspectiva socioambiental dos futuros engenheiros, possibilitando um olhar crítico e a ruptura com o atendimento exclusivo dos interesses corporativos globais, focados exclusivamente na eficiência e eficácia das competências técnicas, cada vez mais focados no ambiente como recurso estratégico, corroborando com a literatura sobre a crise ambiental brasileira (LEANDRO et al., 2015). Nesse sentido, lembra Rodrigues (2018, p.135) ao afirmar que:

tornar-se responsável seria o verdadeiro papel formativo do engenheiro que, no uso da engenhosidade, possa fazer existir os elementos do processo civilizatório e encontra-se em diversos planos de cursos no conceito de 'cidadania'.

Por fim, sabendo do impacto positivo da Graduação sobre as representações sociais, reforça-se a necessidade de se propor currículos capazes, não só de conferir habilidades e competências técnicas aos futuros engenheiros, mas sobretudo de romper com o enfoque exclusivamente utilitário e antropocêntrico de ambiente. Esse enfoque se evidencia, nesta pesquisa, na desconsideração frequente do direito de outras formas de vida à água, do valor do rio como paisagem e lugar de lazer e a falta de uma ética que reconheça o direito de existência dos demais seres. Por outro lado, o comparecimento, nas justificativas, da ideia de proteção "por todos nós" revela, ainda que de modo indireto e escasso, o senso de responsabilidade e de coletividade, que necessita ser consolidado.

\section{Conclusão}

Considera-se que, de modo geral, as evocações dos estudantes correspondem em parte às evocações da população valadarense, mesmo antes do desastre, em que a poluição aparece como elemento central das representações sociais em relação ao Rio Doce. Portanto, esse aspecto, que já estava presente nas representações da população valadarense em geral, antes do desastre e se mantém depois desse. A água é parte central do núcleo de representações do rio Doce para os estudantes entrevistados, em que essa é evocada enquanto recurso necessário para os seres humanos, segundo uma perspectiva antropocêntrica e utilitária. Por outro lado, também o desastre da mineração compareceu no núcleo central, assim como o senso de necessidade de proteção coletiva do rio Doce.

Além disso, nota-se a partir da comparação das evocações de estudantes de diferentes períodos, que a graduação possibilita que conceitos sejam incorporados às representações dos estudantes, que por sua vez, deixam de pensar somente com base no contexto atual para realinhar o pensamento na direção de uma percepção mais ampla e independe de impactos atuais, passados, ou futuros, incluindo em sua análise elementos que se mantém em todos esses espaços.

O olhar detalhado para o processo de construção das representações dos estudantes e os efeitos da formação desses sujeitos ao longo da Graduação revela que, se por um lado há predomínio dos aspectos pessoais sobre os técnicos, por outro a Graduação tem influência importante na ampliação do olhar dos engenheiros para o ambiente. Nesse sentido, destaca-se a importância da Educação Ambiental e formação crítica no Ensino Superior, como forma de ampliar a compreensão dos futuros profissionais.

\section{Agradecimentos}

A Amanda Alves Pereira e Leonardo Sousa Barbosa pelo suporte na coleta de dados, Leonardo Oliveira Leão e Silva pelo auxílio nas análises. As valiosas contribuições dos dois revisores anônimos. FAPEMIG, CAPES, ANA e CNPq pelo apoio financeiro.

\section{Referências}

ABRIC, J.C. L'organisation interne des representations sociales: système central et système périphérique. In: GUIMELLI, C. (Org.) Structures et transformatwns des representations sociales. Neuchâtel: Delachaux et Niestlé. 1994.

AMORIM, M.M.A. et al. Representações sociais do Rio Doce e suas enchentes em Governador Valadares/Brasil. Desenvol. Meio Amb.e, v.49, p.17-35, 2018. doi: 10.5380/dma.v49i0.

ARRUDA, Â. Teoria das representações sociais e teorias de gênero. Cad. Pesq., n.117, p.127-147, 2002.

BAZZO, W.A.; PEREIRA, L.T.V. Ensino de Engenharia: na busca do seu aprimoramento. Florianópolis: Universidade Federal de Santa Catarina, 1997.

BECK, U. Sociedade de risco: rumo a uma outra modernidade. São Paulo: 34, 2011.

BORBA, M.L.G.; DO AMARAL PORTO, M.F. A relevância da relação entre o técnico-científico e o sociopolítico segundo a malha de disciplinas do Curso de Graduação em Engenharia Civil. Rev. Ens. Engenharia, v.32, n. 1, p.43-55, 2014.

BRAGA, B. et al. Introdução à engenharia ambiental. São Paulo: Person Prentice Hall, 2005.

CAVALCANTE, Z.V; SILVA, M.L.S. A importância da revolução industrial no mundo da tecnologia. 2011. Maringa. Anais Eletrônicos... Maringá: CESUMAR, 2011.

CHAVES, A.M.; SILVA, P.L. Representações sociais. In: CAMINO, L. et al. (Org.). Psicologia social: temas e teorias. Brasília: Techno Politik, 2013. p.411-465.

COCIAN, L.F.E. Descobrindo a engenharia: a profissão. Luis Fernando Espinosa: Cocian, 2009.

CNE - Conselho Nacional de Educação. Câmara de Educação Superior. Resolução CNE/CES 11/2002. Diário Oficial da União, Brasília, 09 de abril de 2002. Seção 1, p. 32.

COMPANHIA VALE DO RIO DOCE. Desenvolvimento agropecuário da região de influência da CVRD: estudo básico. Planejamentos Agro-Industriais - SEITEC, São Paulo, 1969.

DAGNINO, R.; NOVAES, H.T.; FRAGA, L. $O$ engenheiro e a sociedade: como transformar a sociedade de classes através da ciência e tecnologia. Florianópolis: Insular, 2013.

FIBRA, Federação das Indústrias do Distrito Federal. Construção Civil representa 6,2\% do PIB do Brasil. Distrito Federal, 2017. Disponível em: <https://www.sistemafibra.org.br/fibra/sala-deimprensa/noticias/1315-construcao-civil- representa-6-2-do-pib- 
brasil>. Acesso em: 30 maio 2019.

HOLTZAPPLE, M.; REECE, W. Introdução à engenharia. Rio de Janeiro: LTC, 2014.

IBGE - Instituto Brasileiro de Geografia e Estatística. Departamento de População; Indicadores Sociais. Tendências demográficas: uma análise dos resultados da sinopse preliminar do censo demográfico 2000. Rio de Janeiro: IBGE, 2001.

LAUDARES, J.B.; RIBEIRO, S. Trabalho e formação do engenheiro. Rev. Bras. Estudos Pedagógicos, v.81, n.199, p.491500, 2007. doi: 10.24109/2176-6681.rbep.81i199.967

LEANDRO, L.A. et al. O futuro da gestão socioambiental: uma análise crítica sobre a crise ambiental brasileira. GeAS, v.4, n.2, p.144-162, 2015. doi: 10.5585/geas.v4i2.322

MARQUES, L. C. Capitalismo e colapso ambiental. São Paulo: Unicamp, 2016.

MEDRADO, B. Produção de sentidos no cotidiano: uma abordagem teórica metodológica para análise das práticas discursivas. In: SPINK, M. (Org.). Práticas discursivas e produção de sentidos no cotidiano: aproximações teóricas e metodológicas. São Paulo: Cortez, 2004.

MILANEZ, B; LOSEKANN, C. Desastre no vale do rio doce: antecedentes, impactos e ações sobre a destruição. Rio de Janeiro: Folio. Digital: Letra e Imagem, 2016.

MILITITSKY, J. O desafio de formar engenheiros como transformadores sociais. Editorial ao Suplemento Engenharia, encartado no jornal Gazeta Mercantil/RS de 17 de agosto de 1998.

MOSCOVICI, S. La psychanalyse, son image et son public. Paris: Presses Universitaires de France, 1976.

MOSCOVICI, S. On social representations. London: Academic Press, 1981.

NEVES, D.A.B. et al. Protocolo verbal e teste de associação livre de palavras: perspectivas de instrumentos de pesquisa introspectiva e projetiva na ciência da informação. Ponto de Acesso, v.8, n.3, p.64-79, 2014.

OLIVEIRA, D. D. et al. Análise de evocações livres: uma técnica de análise estrutural das representações sociais. In: MOREIRA, A.S.P. et al. Perspectivas teórico-metodológicas em representações sociais. João Pessoa, UFPB, 2005.

REIGOTA, M. Meio ambiente e representação social. São Paulo: Cortez, 2004.
RODRIGUES, R. A educação em ciências: o caso da formação escolar em engenharia. Rev. Ciênc. Human., v.11, n.2, p.121-136, 2018. doi: 10.32813/rchv11n22018artigo10

SÁ, C. P. Núcleo central das representações sociais. Petrópolis: Vozes, 1996.

SAMARCO. Rompimento da barragem de Fundão. 2016. Disponível em <http://www.samarco.com/rompimento-dabarragem-de-fundao/>. Acesso em: 17 jun. 2019.

SCHUCH, D.S. et al. O uso de instrumentos teórico metodológicos da representação social na pesquisa em educação ambiental. In: EDUCERE. Curitiba: Champagnat, 2013. Disponível em: $<$ https://educere.bruc.com.br/arquivo/ pdf2008/678_425.pdf $>$. Acesso em: 17 jun. 2019.

SOUZA, B.A.; OLIVEIRA, E.; BARBOSA, S.H.V. Vale do rio de lama - nos rastros da destruição: o documentário em tempos de transmidialidade). In: CONGRESSO BRASILEIRO DE CIÊNCIAS DA COMUNICAÇÃO, 39., São Paulo, 2016.

SPADOTTO, A. et al. O Impactos ambientais causados pela construção civil. Unoesc \& Ciência - ACSA, v.2, n.2, p.173-180, 2011.

SPINK, M.J.P. O conceito de representação social na abordagem psicossocial. Cad. Saúde Pública, v.9, n.3, p.300-308, 1993. doi: 10.1590/ S0102-311X1993000300017

TECHIO, E.M.; GONÇALVES, J.P.; COSTA, P.N. Representação social da sustentabilidade na construção civil: a visão de estudantes universitários. Amb. Soc., v.19, n.2, p.187-204, 2016. doi: 10.1590/1809-4422ASOC130991V1922016.

UNIVERSIDADE VALE DO RIO DOCE - UNIVALE. Plano de Desenvolvimento Institucional - PDI, 2017-2021. Governador Valadares: Universidade Vale do Rio Doce - UNIVALE, 2017.

VASCONCELOS, J.M.C. Espelhos d'água: representações sociais de crianças de Governador Valadares sobre o Rio Doce. Governador Valadares: Universidade Vale do Rio Doce, 2017.

WRIGHT, J.T.C.; SILVA, A.T.B.; SPERS, R.G. O mercado de trabalho no futuro: uma discussão sobre profissões inovadoras, empreendedorismo e tendências para 2020. RAI, v.7, n.3, p.174197, 2010.

ZHOURI, A. et al. Desastre no rio Doce: entre as políticas de reparação e a gestão das afetações. In: ZHOURI, A (Org.) Mineração, violências e resistências: um campo aberto à produção do conhecimento no Brasil. Marabá: Editorial iGuana; ABA, 2018. p.28-64. 